\title{
Erratum to: Solution of the equations for one-dimensional, two-phase, immiscible flow by geometric methods
}

\author{
Ivan Boronin $^{1}$ • Andrey Shevlyakov ${ }^{1}$ (D)
}

Published online: 28 February 2017

(C) Springer International Publishing 2017

\section{Erratum to: Anal.Math.Phys. DOI 10.1007/s13324-016-0157-1}

Unfortunately, the given name and family name of the authors were incorrectly published in the original publication. The correct given name and family name should read as 'Ivan Boronin' and 'Andrey Shevlyakov'. The original article was corrected.

The online version of the original article can be found under https://doi.org/10.1007/s13324-016-0157-1.

$凶$ Andrey Shevlyakov aash29@gmail.com

Ivan Boronin anarsul123@yandex.ru

1 Institute of Control Sciences, Profsoyuznaya, 65, Moscow 117997, Russia 